\title{
Self-Reported Psychopathic Traits in Children: Their Stability and Concurrent and Prospective Association with Conduct Problems and Aggression
}

\author{
Yoast van Baardewijk • Robert Vermeiren • \\ Hedy Stegge • Theo Doreleijers
}

Published online: 15 January 2011

(C) Springer Science+Business Media, LLC 2011

\begin{abstract}
The current study investigated the 18-month stability of self-reported psychopathic traits measured through the Youth Psychopathic traits Inventory-Child Version (YPI-CV) and their concurrent and prospective associations with conduct problems and aggression in a sample of $9-12$ year olds ( $n=159,52 \%$ boys $)$ from the community. Self-reported psychopathy scores were moderately to highly stable and traits were positively related to conduct problems both concurrently and at follow-up, the latter even after controlling for initial levels of conduct problems. Higher self-reported psychopathic traits were also related to higher reactive, but particularly proactive aggression at follow-up. Finally, children with persistently high levels of psychopathic traits exhibited higher levels of conduct problems and proactive aggression at follow-up than those with unstable or stable low psychopathic traits.
\end{abstract}

Y. van Baardewijk

Forensisch Centrum Teylingereind,

Sassenheim, The Netherlands

Y. van Baardewijk ( $\square)$

PO Box 36254, 1020 MG, Amsterdam, The Netherlands

e-mail: yoast_vb@dds.nl

R. Vermeiren

Curium-Leiden University Medical Center,

Oegstgeest, The Netherlands

R. Vermeiren $\cdot$ T. Doreleijers

Department of Child and Adolescent Forensic Psychiatry,

VU University Medical Center,

Amsterdam, The Netherlands

H. Stegge

Department of Developmental Psychology, VU University,

Amsterdam, The Netherlands
Keywords Psychopathy · Children · Self-report · Conduct problems $\cdot$ Aggression

\section{Introduction}

Psychopathy stands for a constellation of personality traits such as callousness, manipulativeness, egocentricity, impulsivity and a need for stimulation (e.g. Hare 2003). This spectrum of characteristics can be classified in three dimensions: affective callous-unemotional, interpersonal grandiose-manipulative and impulsive and irresponsible traits (Cooke and Michie 2001). Psychopathy is a well documented predictor of violence and criminality among adults (Douglas et al. 2006; Hare 2003; Leistico et al. 2008) and it is therefore not surprising that an increasing number of studies focuses on psychopathic traits in younger age groups. The majority of these studies have pertained to adolescent populations (for reviews see Dolan 2004; Edens et al. 2001; Salekin 2006), but a growing number of studies has also tested the psychopathy concept in preadolescent children. As will be detailed below, at a young age, these traits show notable similarities to those in adults in a number of key respects: factor structure, stability over time and relation to criterion variables.

With respect to the factor structure, psychopathic traits in children have been demonstrated to combine into the same three dimensions that comprise adult psychopathy (Bijttebier and DeCoene 2009; Frick et al. 2000; Van Baardewijk et al. 2008). Although, like in adulthood (e.g. Hare 2003), other factor structures have also been described (e.g. a 5-factor structure; Dadds et al. 2005 and a 2-factor structure; Frick et al. 2000; Frick et al. 1994).

With respect to stability, if the concept of child psychopathy is to be viable, it should demonstrate 
significant stability over time both during childhood and into adolescence (Andershed 2010; Seagrave and Grisso 2002). Indeed, both at mean and rank order level, psychopathic traits have shown moderate to high stability across childhood and into adolescence in various samples, over periods ranging from 1 to 10 years (Barry et al. 2008; Dadds et al. 2005; Frick et al. 2003b; Lynam et al. 2009; Obradovic et al. 2007). Interestingly, recent studies looking at individual level stability have demonstrated that higher stability of psychopathic traits in youth was predictive of worse outcome (i.e. higher levels of antisocial personality characteristics in young adulthoods; Pardini and Loeber 2008) and worse outcome of a parent-training intervention in young boys (Hawes and Dadds 2007), which suggests that it is worthwhile to focus on the predictive utility of differences in the stability of psychopathic traits.

Finally, if psychopathy is a viable construct in children, one would expect to find relations to criterion variables analogous to those in adults. Psychopathy in adults is strongly related to concurrent and future antisocial behaviors such as delinquency and aggression (e.g. Leistico et al. 2008; Hare 2003). Offenders high in psychopathic traits commit both more and more varied crimes than offenders with low levels of these traits (e.g. Hare 2003; Kosson et al. 1990). The crimes they commit are more violent in nature, and they show a particular disposition toward a premeditated, proactive or instrumental type of violence (Cima-Knijff and Raine 2009; Cornell et al. 1996; Porter and Woodworth 2006). As expected, similar findings with respect to antisocial behaviors have been described in children. While little is known about the relationship between psychopathic traits in preadolescent children and criminality, higher levels of these traits are associated with more severe conduct problems, both concurrently and predictively over follow-up periods ranging from 1 to 7 years (Christian et al. 1997; Dadds et al. 2005; Frick et al. 2003a; Kimonis et al. 2006; Lynam 1997; Piatigorsky and Hinshaw 2004). With respect to violence and aggression, like psychopathic adults, children with psychopathic traits show elevated levels of proactive or instrumental aggression, in addition to high levels of reactive aggression (Frick et al. 2003a; Waschbusch and Willoughby 2008).

To conclude, these findings with respect to the factor structure of psychopathy, the stability and the concurrent and prospective relationships to antisocial problems, which mimic findings in adult samples, suggest that the concept of psychopathy is viable in preadolescent youth. (For reviews, which also cover similarities pertaining to emotional and cognitive functioning, see e.g. Farrington 2005; Frick and White 2008; Johnstone and Cooke 2004; Kotler and McMahon 2010; Lynam and Gudonis 2005).

A recent development in the discussion concerning psychopathic traits in children pertains to the use of informants. All cited studies investigating psychopathic traits in children have relied on parent and/or teacher report, with the majority of those using versions of the Antisocial Process Screening Device (APSD; Frick and Hare 2001). However, correlations between scores on measures of psychopathy using different informants have generally been low, possibly indicating that a single (external) source of information is not covering the full manifestation of the construct. In fact, for a number of reasons, the use of an internal source (i.e. self-report) may provide an important perspective on children's psychopathic traits in addition to external, third party reports. First, in general, children are in the unique position to report on behaviors across a range of situations, including the home, the classroom and the playground. Second, specific to psychopathy, internal emotional states central to the psychopathic constellation, such as the lack of empathy or guilt, may be more evident to children themselves than to untrained observers such as parents or teachers (Andershed et al. 2002; Muñoz and Frick 2007). There is reason to assume that preadolescent children themselves are indeed capable of rating these traits through self-report as children from approximately 9 years of age have been shown to reliably and meaningfully report on constructs related to psychopathy such as empathy (Bryant 1982), guilt (Ferguson et al. 2000) and narcissism (Thomaes et al. 2008). Only one empirical study to date has focused uniquely on the utility of self-report for measuring psychopathic traits (Van Baardewijk et al. 2008). It involved the validation of a downward extension of the well-known adolescent Youth Psychopathic traits Inventory (YPI; Andershed et al. 2002). This child instrument, named the Youth Psychopathic traits Inventory-Child Version (YPI-CV), is an age-appropriate adaptation of the adolescent instrument that matches the cognitive, emotional and verbal development and social realities of 9-12 year olds. The validation study (Van Baardewijk et al. 2008) reported excellent results with respect to the internal consistency of the measure: a three factor structure similar to its adolescent counterpart, comprising the three core personality dimensions of psychopathy (Cooke and Michie 2001; grandiosemanipulative traits, callous-unemotional traits and impulsive-irresponsible traits and behaviors) with high Cronbach's alphas (.80-.92) and test-retest reliability coefficients (ICCs) over 2 and 6 months of .77 and .76, respectively.

The current study sought to expand on these findings by investigating the stability of self-reported psychopathic traits over time and by examining the concurrent and prospective association between self-reported psychopathic traits in preadolescent children and antisocial behaviors that have typically been associated with these traits in different age groups: conduct problems and proactive aggression. First, we hypothesized significant stability of self-reported 
psychopathic traits between baseline and follow-up (18 months later). Second, we hypothesized a positive association between self-reported psychopathic traits and conduct problems both concurrently and at follow-up. In assessing conduct problems, both self, peer and teacher reports were used to provide a wide scope on children's behaviors. Third, we hypothesized self-reported psychopathic traits to be related to aggression at follow-up, particularly to proactive aggression. Finally, as recent research suggests that differences in levels of stability of psychopathic traits have predictive relevance for future antisocial behaviors, we hypothesized that children with the most stable high selfreported psychopathic traits would show the worst outcome in terms of follow-up conduct problems and aggression.

\section{Method}

\section{Participants}

The participants were obtained from the same four medium sized primary schools in the Netherlands that had participated in the YPI-CV validation study $(n=360$; Van Baardewijk et al. 2008). Before the follow-up assessment, one school $(n=$ 68) declined cooperation stating it was a busy time of the year. Additionally, all children $(n=133)$ who were in grade 8 (the final grade in Dutch primary schools) during baseline assessment had finished their primary education at follow-up and had transferred to various high schools. These children could therefore not be retested and were not included in the present study. This resulted in a final sample size of 159 ( $51.6 \%$ boys). No differences were found between the current sample and the children that could not be followed up in gender $\left(\chi^{2}(1)=2.35, p=.14\right)$, baseline psychopathy scores $(t(313)=.15, p=.88)$, self rated conduct problems $(t(358)=-.29, p=.77)$, teacher rated conduct problems $(t(363)=1.39, p=.16)$ or peer rated conduct problems $(t$ $(327)=.54, p=.94)$. Age, however, did differ significantly between these samples as it were the oldest children at baseline assessment that finished their primary schooling and had continued their education in high school $(t(365)=11.64$, $p<.000$ ). The average age of the current sample was 10.4 $(S D=.67$; range 9.1-12.3) at baseline assessment, and 11.8 $(S D=.67$; range 10.6-13.7) at follow-up. The average age of children that were not followed up was $11.35(S D=.91)$ at baseline assessment. Most children (85\%) were Caucasian; $15 \%$ had other (e.g. Surinam, Lesser Antilles, North African) or mixed ethnic/cultural origins.

\section{Measures}

Youth Psychopathic Traits Inventory-Child Version (YPI$C V)$ Psychopathic traits were assessed using the Youth
Psychopathic traits Inventory-Child Version (Van Baardewijk et al. 2008), a 50-item self-report instrument measuring the three core personality dimensions of psychopathy: grandiose-manipulative traits (sample item: "It's fun to make up stories and try to get people to believe them.") callousunemotional traits (sample item: "Feeling bad when you have done something wrong is a waste of time.") and impulsive-irresponsible traits and behaviors (sample item: "I find rules to be nothing but a nuisance"). Items are scored on a 4 -point scale $(1=$ does not apply at all $-4=$ applies very well). The instrument was adapted from the original Youth Psychopathic traits Inventory intended for adolescents (YPI; Andershed et al. 2002). The current child version was developed for use in 9-12 year olds. Confirmatory factor analyses showed the three-factor structure to be similar to that of the original adolescent version, with comparative fit indices (CFI) ranging from .91 to .96 and root mean square errors of approximation (RMSEA) ranging from .08 to .06 (Van Baardewijk et al. 2008). The correlation between the factors ranged from .62 to .76 . Cronbach's alphas of the total score and factors ranged between .80 and .92 and test-retest reliability coefficients (ICC's) over 2 and 6 months were .77 and .76 respectively. The instrument is available in English and Dutch. Cronbach's alphas of both administrations of the YPI-CV, as well as all other measures, are reported in Table 1.

Strengths and Difficulties Questionnaire (SDQ)—Conduct Problems Scale The Strengths and Difficulties Questionnaire (Goodman 1997) is a widely used 25-item behavioral screening device, including both teacher/parent and selfreport versions. In the current study, only the self-report version was used, which is intended for 11-16 year olds, but has been used successfully in 8-13 year old Dutch nonclinical children as well (Muris et al. 2004). The measure is scored on a three-point scale: not at all true-somewhat true - certainly true. The instrument assesses five domains: emotional symptoms, conduct problems, hyperactivity/ inattention, peer relationship problems and prosocial behavior. The internal consistency and construct validity of the SDQ, including the Dutch version, has been reported to be satisfactory (Goodman 1997; Muris et al. 2004). Only the conduct problems scale will be reported on in the current study. Sample item: "I am often accused of lying or cheating". As can be seen in Table 1, the Cronbach's alphas of this subscale were not fully satisfactory.

Problem Behavior at School Interview (PBSI)—CD/ODD Scales Teacher-reported conduct problems were assessed using the ODD and CD scales from the Problem Behavior at School Interview (Erasmus MC, 2000) a 32-item teacher interview assessing problem behavior in children. In the current study a paper and pencil version was used. Teachers 
Table 1 Descriptive statistics for baseline and follow-up measures

\begin{tabular}{|c|c|c|c|c|c|c|c|c|}
\hline & \multicolumn{4}{|c|}{ Baseline assessment } & \multicolumn{4}{|c|}{ Follow-up assessment } \\
\hline & Mean score & $S D$ & Range & $\begin{array}{l}\text { Cronbach's } \\
\text { alpha }\end{array}$ & $\begin{array}{l}\text { Mean } \\
\text { score }\end{array}$ & $S D$ & Range & $\begin{array}{l}\text { Cronbach's } \\
\text { alpha }\end{array}$ \\
\hline YPI-CV Psychopathy total score & 1.63 & .40 & $1.02-3.40$ & .92 & 1.63 & .37 & $1.00-2.74$ & .92 \\
\hline YPI-CV Callous-Unemotional dimension & 1.61 & .46 & $1.00-3.47$ & .80 & 1.49 & .40 & $1.00-3.13$ & .82 \\
\hline YPI-CV Grandiose-Manipulative dimension & 1.42 & .41 & $1.00-3.40$ & .89 & 1.40 & .36 & $1.00-2.75$ & .87 \\
\hline YPI-CV Impulsive-Irresponsible dimension & 1.92 & .54 & $1.00-3.60$ & .85 & 2.05 & .57 & $1.00-3.73$ & .87 \\
\hline PBSI conduct problems (teacher) & .54 & .64 & $.00-2.58$ & .89 & .74 & .78 & $.00-3.79$ & .94 \\
\hline SDQ conduct problems (self) & .40 & .33 & $.00-1.40$ & .57 & .38 & .32 & $.00-1.60$ & .53 \\
\hline PMIEB conduct problems (peers) & 1.63 & 2.62 & $.00-18$ & .88 & 5.17 & 7.97 & $.00-34$ & .86 \\
\hline RPQ reactive aggression & & & & & .72 & .36 & $.00-1.82$ & .86 \\
\hline RPQ proactive aggression & & & & & .17 & .24 & $.00-1.33$ & .84 \\
\hline
\end{tabular}

YPI-CV Youth Psychopathic traits Inventory-Child Version, SDQ Strengths and Difficulties Questionnaire, PBSI Problem Behavior at School Interview, $P M I E B$ Peer-report Measure of Internalizing and Externalizing Behavior, $R P Q$ Reactive and Proactive Aggression Questionnaire

rated each child's behavior on a 5-point scale. The ODD symptoms scale comprises 5 items (e.g. "This child is disobedient) and the CD symptoms scale comprises 7 items (e.g. "This child steals"). The two scales were combined to form one problem behavior scale.

Peer-Report Measure of Internalizing and Externalizing Behavior (PMIEB) Peer-rated conduct problems were assessed using the Peer-report Measure of Internalizing and Externalizing Behavior (Weiss et al. 2002), a well established peer-nomination inventory that assesses psychopathology in school-aged children. Participants were asked to select up to three of their classmates who best fit the 4-item description of conduct problems. Sample item: "Select up to three children who are not always honest" and "Select up to three children who take things that do not belong to them". The number of nominations were calculated for each child and standardized within classes to control for class size.

Reactive and Proactive Aggression Questionnaire The RPQ (Raine et al. 2006) is a brief 23 item self-report measure aiming to measure reactive aggression (sample item: "How often have you damaged things because you felt mad") and proactive aggression (sample item: "How often have you had fights with others to show who was on top"). The two forms of aggression were highly correlated in our sample $(r=.68, p<.000)$. This is consistent with the RPQ validation study (Raine et al. 2006) and numerous other studies investigating proactive and reactive aggression. Therefore, in addition to calculating the 'raw' reactive and proactive aggression scores, Raine et al. (2006) proposed calculating residual scores as measures of 'pure' reactive and proactive aggression. This was done by regressing proactive aggression onto reactive aggression, and vice versa, and saving the standardized residuals.

\section{Procedure}

The baseline (December 2005) and the follow-up assessments (June 2007) were 18 months apart. Teachers had worked with the children for at least 3 months at each assessment, children had known each other for several years. At both assessments, parental consent was obtained. At baseline assessment, 95\% allowed their child to take part in the study, and 99\% did so at follow up. At each assessment children filled out their questionnaires during regular school time. Before starting the assessment, each participant was informed about the aims and the duration of the assessment. It was emphasized that participation in the study was voluntary and that the participant could refrain from participating at any moment, without giving an explanation. Furthermore, it was pointed out to all participants that the results would remain confidential and that neither parents nor teachers would be informed of their individual answers. Teacher reports were collected at both time points. All questionnaires were filled out both at baseline and at follow-up assessment, except for the RPQ aggression questionnaire, which was only administered at follow-up. At baseline assessment, schools were paid $€ 200$ in gift vouchers for their cooperation, no compensation was given at the follow-up assessment.

\section{Results}

Table 1 displays the untransformed descriptive statistics for both the baseline and follow-up measures. Overall, behavior 
problems and aggression measures were positively skewed, which is common in non-referred samples as these are generally characterized by low levels of externalizing symptomatology. Therefore, square root transformations were performed prior to further analyses.

\section{Stability of Self-Reported Psychopathic Traits}

Stability of psychopathic traits measured using the YPI-CV was assessed over a period of 18 months. Consistent with previous studies in this field (e.g. Barry et al. 2008; Frick et al. 2003b) average measure intraclass correlation coefficients (ICCs) with an absolute agreement definition were used. ICCs were .73 for the YPI-CV total score, .63 for the Callous-Unemotional dimension, .59 for the GrandioseManipulative dimension and .76 for the ImpulsiveIrresponsible dimension. These results indicate moderate to high stability over a period of 18 months (Andershed 2010).

Concurrent and Prospective Relationships

Between Self-Reported Psychopathic Traits and Conduct

Problems and Aggression

Conduct Problems Table 2 shows zero-order correlations between baseline YPI-CV total score and factor scores and peer and teacher reported problem behavior measured at baseline and follow-up. Partial correlations, controlling for the baseline conduct problems and semi-partial correlations, controlling for the baseline conduct problems and the other two dimensions are also reported in Table 2.

Table 2 revealed significant associations between YPI$\mathrm{CV}$ total score and factor scores and all measures of conduct problems, both concurrently and prospectively. The partial correlations showed that psychopathic traits were related to follow-up conduct problems even after controlling for initial levels of these problems, although a number of partial relations just failed to reach conventional levels of significance, mainly those involving the GrandioseManipulative dimension. The semi-partial correlations showed that, when controlling for the other dimensions, the Impulsive-Irresponsible dimension was uniquely related to concurrent and follow-up conduct problems.

Proactive and Reactive Aggression To investigate the prospective relationship between self-reported psychopathic traits and aggression, correlations between baseline YPI-CV scores and reactive and proactive aggressive behaviors at follow-up were calculated. Correlations between baseline psychopathy scores and both 'raw' and residual proactive and reactive aggression at follow-up are displayed in Table 3. As can be read from Table 3 the YPI-CV total score and all dimension scores were positively related to 'raw' proactive and reactive aggression at follow-up. YPI-CV scores were also positively related to residual proactive aggression but not to residual reactive aggression. Again, after controlling for the other two dimensions, the Impulsive-Irresponsible dimension was uniquely related to follow-up proactive aggression

The Relationship Between Stability of Self-Reported Psychopathic Traits and Conduct Problems and Aggression

To investigate whether the 18-month stability of psychopathy scores would be related to conduct problems and aggression at follow up, a stability variable was composed based on a median split on both baseline and follow-up YPI-CV total scores following the procedure by Hawes and Dadds (2007). Three stability groups were created. One group consisted of children whose scores were below the median on both assessments ('stable low'-group; $n=58$ ), one group consisted of children whose scores were above the median on both assessments ('stable high'-group; $n=51$ ) and finally, one group consisted of children whose scores were above the median at baseline assessment and below the median at follow-up assessment, or vice versa ('unstable'-group; $n=$ 50). A series of ANOVA analyses were conducted to determine whether the stability groups differed in levels of follow-up conduct problems and aggression. Significant main effects were found for the YPI-CV total score on all follow-up measures of conduct problems (ranging from $F=$ $4.00, p<.05$ to $F=16.92, p<.000$ ) and on residual proactive aggression (ranging from $F=8.16, p<.000$ ) indicating differences between the stability groups on these variables. For residual reactive aggression, no significant main effects were found. To identify the differences in levels of conduct problems and residual proactive aggression at follow-up between the three stability groups, posthoc analyses with Bonferonni correction for multiple comparisons were performed. All scores were standardized (Z-scores with $M=0$ and $S D=1)$ to aid in the interpretation. Table 4 shows the difference in levels of follow-up conduct problems and aggression between stability groups. With few exceptions, the 'stable high' groups displayed significantly higher scores than both other groups on conduct problems and residual proactive aggression at follow-up. The 'unstable' and 'stable low' groups did not differ significantly on any of the measures and are not displayed in the table. To aid in the interpretation, Fig. 1 shows the standardized mean scores of all outcome variables as a function of stability of psychopathic traits (total score of the YPI-CV).

\section{Discussion}

The current study investigated the 18-month stability of self-reported psychopathic traits and their associations with 


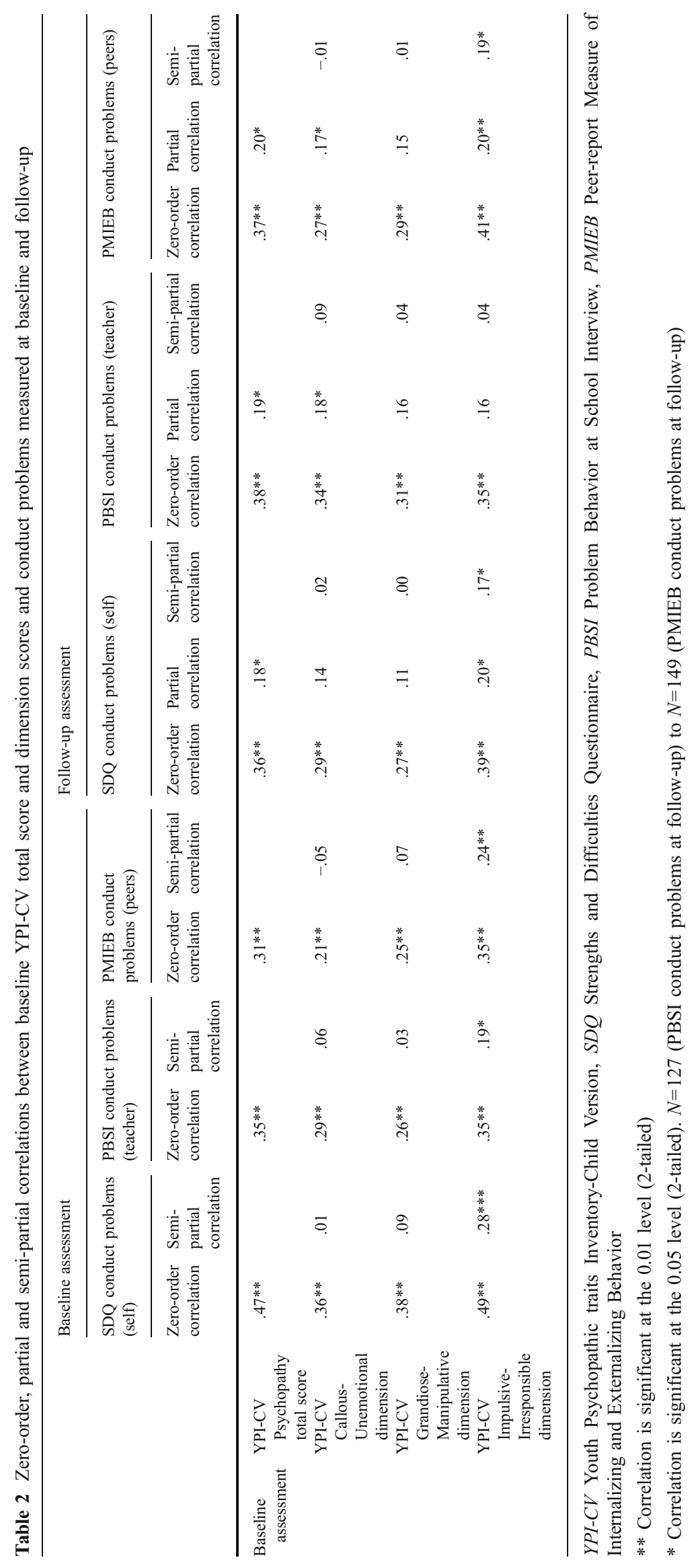


Table 3 Zero-order correlations between baseline YPI-CV total score and dimension scores and residual proactive and reactive aggression at follow-up

\begin{tabular}{|c|c|c|c|c|c|c|c|c|c|}
\hline & & \multicolumn{8}{|c|}{ Follow-up assessment } \\
\hline & & \multicolumn{2}{|c|}{$\begin{array}{l}\text { RPQ proactive } \\
\text { aggression }\end{array}$} & \multicolumn{2}{|c|}{$\begin{array}{l}\text { RPQ reactive } \\
\text { aggression }\end{array}$} & \multicolumn{2}{|c|}{$\begin{array}{l}\text { RPQ residual proactive } \\
\text { aggression }\end{array}$} & \multicolumn{2}{|c|}{$\begin{array}{l}\text { RPQ residual reactive } \\
\text { aggression }\end{array}$} \\
\hline & & $\begin{array}{l}\text { Zero-order } \\
\text { correlation }\end{array}$ & $\begin{array}{l}\text { Semi-partial } \\
\text { correlation }\end{array}$ & $\begin{array}{l}\text { Zero-order } \\
\text { correlation }\end{array}$ & $\begin{array}{l}\text { Semi-partial } \\
\text { correlation }\end{array}$ & $\begin{array}{l}\text { Zero-order } \\
\text { correlation }\end{array}$ & $\begin{array}{l}\text { Semi-partial } \\
\text { correlation }\end{array}$ & $\begin{array}{l}\text { Zero-order } \\
\text { correlation }\end{array}$ & $\begin{array}{l}\text { Semi-partial } \\
\text { correlation }\end{array}$ \\
\hline \multirow[t]{4}{*}{$\begin{array}{l}\text { Baseline } \\
\text { assessment }\end{array}$} & $\begin{array}{l}\text { YPI-CV Psychopathy } \\
\text { total score }\end{array}$ & $52 * *$ & & $.44 * *$ & & $.30 * *$ & & .10 & \\
\hline & $\begin{array}{l}\text { YPI-CV Callous- } \\
\text { Unemotional dimension }\end{array}$ & $.41^{* *}$ & .02 & $.31 * *$ & -.08 & $.28 * *$ & .10 & .02 & -.12 \\
\hline & $\begin{array}{l}\text { YPI-CV Grandiose- } \\
\text { Manipulative dimension }\end{array}$ & $.39 * *$ & .05 & $.35^{* *}$ & .08 & $.21 *$ & .07 & .10 & .06 \\
\hline & $\begin{array}{l}\text { YPI-CV Impulsive- } \\
\text { Irresponsible dimension }\end{array}$ & $.55^{* *}$ & $.34 * *$ & $.49 * *$ & $.36^{* *}$ & $.31 *$ & $.22 *$ & .13 & .07 \\
\hline
\end{tabular}

$Y P I-C V$ Youth Psychopathic traits Inventory-Child Version, $R P Q$ Reactive and Proactive Aggression Questionnaire

** Correlation is significant at the 0.01 level (2-tailed)

* Correlation is significant at the 0.05 level (2-tailed), $N=146$

conduct problems and aggression in a sample of 9-12 year old children from the community. Furthermore, we investigated whether individuals showing higher levels of stability of psychopathic traits had higher levels of followup conduct problems and aggression. As expected, YPI-CV scores were found to be moderately to highly stable over 18 months. These stability indices were largely comparable to previous findings over comparable periods, both in adolescents and children (Andershed 2010). We found selfreported psychopathic traits to be related to higher rates of conduct problems both concurrently and at follow-up. These relations generally remained even after controlling for initial conduct problems and were consistent over reporters. Those partial correlations were modest in size, but it should be noted that the stability of conduct problems was quite high (baseline to follow-up correlations ranged from .5 for self-report to .8 for peer-report), which leaves little room for statistically significant added value of other concepts. When controlling for the other two dimensions, the Impulsive-Irresponsible traits showed uniquely related to concurrent and follow-up conduct problems. Findings pertaining to the relation with aggression were also generally consistent with our hypothesis. They showed self-reported psychopathic traits to be associated with proactive as well as reactive aggression at follow-up. When controlling for the overlap between proactive and reactive aggression, thereby separating the two and creating 'pure' measures of proactive and reactive aggression, only the relation between psychopathic traits and proactive aggression remained. This is in line with earlier findings in adult, adolescent and child psychopathy research that has shown psychopathic traits to be related to both types of aggression, but particularly to premeditative, goal-directed and 'cold blooded' proactive forms of aggression not shared by those with low psychopathic traits (Flight and Forth 2007; Frick et al. 2003a; Porter and Woodworth 2006; Waschbusch and Willoughby 2008). Again, after controlling for the other two dimensions, the Impulsive-irresponsible traits were uniquely related to follow-up proactive aggression.

Our findings somewhat contradict the literature that posits the Callous-Unemotional dimension as most important for predicting more severe or stable conduct problems and aggression in young children (Moran et al. 2008; Burke et al. 2007; Frick et al. 2003a, Frick et al. 2005; Frick and White 2008). However, it should be noted that most of these studies do not actually take into account any dimension of psychopathy other than CU traits (e.g. Burke et al. 2007; Frick et al. 2003a; Frick et al. 2005; Moran et al. 2008) and they generally use a methodology in which the $\mathrm{CU}$ dimension is used to differentiate within antisocial youth. Indeed, the Impulsive-irresponsible dimension of many measures of psychopathy often shows the strongest and most consistent relation to measures of conduct problems, delinquency, and other antisocial indices (Frick et al. 2000; Frick and White 2008; Kotler and McMahon 2010; Lynam and Gudonis 2005),

Regarding the predictive value of the stability of psychopathic traits, the current study showed that children with persistently high levels over a period of 18 months exhibited higher levels of antisocial behaviors (conduct problems and proactive aggression) at follow-up than those with unstable or stable low psychopathic traits. These 
Table 4 Differences between the three YPI-CV stability groups on standardized mean scores of follow-up conduct problems and residual aggression

\begin{tabular}{|c|c|c|c|c|c|c|}
\hline & & \multicolumn{3}{|c|}{ Follow-up conduct problems } & \multicolumn{2}{|l|}{ Follow-up aggression } \\
\hline & & $\begin{array}{l}\text { SDQ conduct } \\
\text { problems (self) } \\
\text { Stable high }\end{array}$ & $\begin{array}{l}\text { PBSI conduct } \\
\text { problems (teacher) } \\
\text { Stable high }\end{array}$ & $\begin{array}{l}\text { PMIEB conduct } \\
\text { problems (peers) } \\
\text { Stable high }\end{array}$ & $\begin{array}{l}\text { RPQ residual } \\
\text { proactive aggression } \\
\text { Stable high }\end{array}$ & $\begin{array}{l}\text { RPQ residual } \\
\text { reactive aggression } \\
\text { Stable high }\end{array}$ \\
\hline \multirow{2}{*}{$\begin{array}{l}\text { YPI-CV Psychopathy } \\
\text { Total score }\end{array}$} & Unstable & .45 & $1.09 * *$ & $.69 * *$ & $.66^{* *}$ & .10 \\
\hline & Stable low & $.76^{* *}$ & $.92 * *$ & $.93 * *$ & $.72 * *$ & .41. \\
\hline
\end{tabular}

Differences are calculated columns-rows. YPI-CV Youth Psychopathic traits Inventory-Child Version, $S D Q$ Strengths and Difficulties Questionnaire, PBSI Problem Behavior at School Interview, PMIEB Peer-report Measure of Internalizing and Externalizing Behavior, RPQ Reactive and Proactive Aggression Questionnaire

** Difference is significant at the 0.01 level (2-tailed). $N($ Stable high $)=51, N($ Unstable $)=50, N($ Stable low $)=58$

findings are consistent with the few studies that have investigated the predictive value of the stability of psychopathic traits in youth and that found high stability of psychopathic traits to predict the seriousness of antisocial behavior in adolescents (Pardini and Loeber 2008) and worse outcome of a parent-training intervention in clinicreferred preadolescent boys (Hawes and Dadds 2007). Interestingly, hardly any differences in follow-up conduct problems and aggression were found between children showing consistently low levels of psychopathic traits and those with high levels at one timepoint only.

The difference between children who have stable psychopathic traits versus unstable or low stable traits may be explained by factors not measured in the current study, such as social relations, parenting or biological markers. For example, Barry et al. (2008) showed social impairment variables mediated the persistence of psycho-

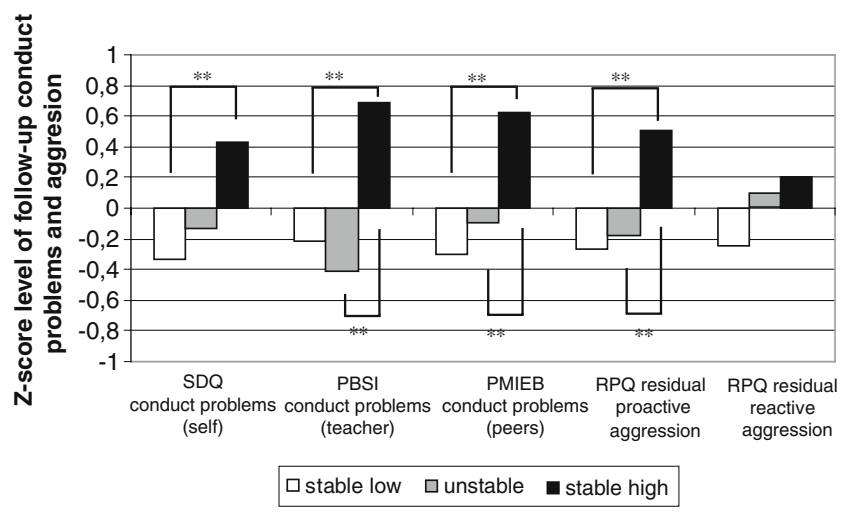

Fig. 1 Differences in follow-up conduct problems and aggression between stability groups of YPI-CV total score. Note: YPI-CV Youth Psychopathic traits Inventory-Child Version, PBSI Problem Behavior at School Interview, $S D Q$ Strengths and Difficulties Questionnaire, $P M I E B$ Peer-report Measure of Internalizing and Externalizing Behavior, $R P Q$ Reactive and Proactive Aggression Questionnaire ** Difference is significant at the 0.01 level (2-tailed). * Difference is significant at the 0.05 level (2-tailed). $N$ (Stable high) $=51$, $N($ Unstable $)=50, N($ Stable low $)=58$ pathic traits. Frick and colleagues (2003b) demonstrated that children's level of conduct problems, the socioeconomic status of the child's family, and the quality of parenting the child received were predictors of the stability of psychopathic traits. Pardini, Lochman and Powell (2007) found that lower levels of anxiety were related to increases in psychopathic traits during a 1-year period only for children who reported experiencing low levels of parental warmth and involvement. It may also be that the psychopathic traits of children who scored occasionally high in our study have a different genetic etiology than those scoring persistently high. Several investigators have speculated that the stability of psychopathic traits is largely driven by neurobiological factors or genetics (Blair et al. 2006; Blonigen et al. 2006; Forsman et al. 2008; Kiehl 2006). Regardless of the causes, the current study supported the notion that higher stability is related to higher levels of problematic outcome and suggests that multiple assessments could add to the predictive accuracy of psychopathy assessment in youth. Concluding, with respect to the stability and concurrent and prospective associations between self-reported psychopathic traits and conduct problems and aggression, our findings confirm past findings in both adolescents (e.g. Andershed et al. 2002, Campbell et al. 2004; Das et al. 2007; Marsee et al. 2005; Pardini and Loeber 2008) and children using teacher and parent report (Christian et al. 1997; Dadds et al. 2005; Hawes and Dadds 2007; Lynam 1997).

With respect to clinical implications of the current study, developing valid measures of psychopathic traits for children is clinically relevant because gaining knowledge about the early development, manifestations, and etiology of these traits are early but necessary steps towards the development of effective interventions for these children. More so, although the YPI-child version was developed primarily as a research instrument, like its adolescent counterpart it may prove useful as clinical assessment tools as well (e.g. Wareham et al. 2009). 
A strength of the current study is use of different informants. Both the child itself, peers and teachers provide a unique perspective on behavioral and social functioning, which in the current study showed consistency. However, the present study should also be seen in the light of a number of limitations that will need addressing in future research. First, as our sample size was modest, our results require replication in larger samples. Second, with respect to results on the predictive utility of stability of psychopathic traits, the current limited design did not allow for a separation of stability of psychopathic traits from overlapping stability of conduct problems in predicting outcome. Even though they are consistent with previous research, the present findings should be interpreted with caution. Furthermore, the use of a median split to create stability groups reduces power and creates artificial homogeneity of the participants within each group. Future studies should therefore continue to investigate the predictive value of repeated assessment of psychopathic traits with more advanced designs and methodologies. Third, as aggression is a component of conduct problems or conduct disorder (APA, 2000) some overlap between these concepts may have occurred in this study. Finally, the reliability of the SDQ conduct problems subscale was lower than commonly recommended. Even though the results using this measure are in line with those found using the peer and teacher reports, they should be interpreted with caution.

To conclude, the cross-sectional validation study of the YPI-CV showed this instrument to be reliable and supported its construct validity (Van Baardewijk et al. 2008). The current study expanded on these findings, showing that scores on the YPI-CV were related to concurrent and future socially harmful behaviors, were relatively stable over time and that higher stability was related to higher levels of conduct problems and aggression. These findings thus further support the notion that psychopathic traits can be measured at a young age and that self-report, by means of the Youth Psychopathic traits Inventory-Child Version, can provide an important additional point of view.

\section{References}

Andershed, H. (2010). Stability of psychopathy: A review of the evidence and suggestions of ways forward. In D. Lynam \& R. T. Salekin (Eds.), Handbook of child and adolescent psychopathy (pp. 233-250). New York: The Guilford Press.

Andershed, H., Kerr, M., Stattin, H., \& Levander, S. (2002). Psychopathic traits in non-referred youths: Initial test of a new assessment tool. In E. S. Blaauw (Ed.), Psychopaths: Current international perspectives (pp. 131-158). The Hague: Elsevier.

APA. (2000). Diagnostic and statistical manual of mental disorders $(D S M-I V)$. Washington: American Psychiatric Association.
Barry, T. D., Barry, C. T., Deming, A., \& Lochman, J. E. (2008). Stability of psychopathic characteristics in childhood: the influence of social relationships. Criminal Justice and Behavior, $35,244-262$.

Blair, R. J. R., Peschardt, K. S., Budhani, S., Mitchell, D. G., \& Pine, D. S. (2006). The development of psychopathy. Journal of Child Psychology and Psychiatry, 47, 262-276.

Blonigen, D. M., Hicks, B. M., Krueger, R. F., Patrick, C. J., \& Iacono, W. G. (2006). Continuity and change in psychopathic traits as measured via normal-range personality: a longitudinalbiometric study. Journal of Abnormal Psychology, 115, 85-95.

Bijttebier, P., \& Decoene, S. (2009). Assessment of psychopathic traits in children and adolescents: further validation of the antisocial process screening device and the childhood psychopathy scale. European Journal of Psychological Assessment, 25, 157-163.

Bryant, B. (1982). An index of empathy for children and adolescents. Child Development, 53, 413-425.

Burke, J. D., Loeber, R., \& Lahey, B. B. (2007). Adolescent conduct disorder and interpersonal callousness as predictors of psychopathy in young adults. Journal of Clinical Child and Adolescent Psychology, 36, 334-346.

Campbell, M. A., Porter, S., \& Santor, D. (2004). Psychopathic traits in adolescent offenders: an evaluation of criminal history, clinical, and psychosocial correlates. Behavioral. Science and the Law, 22, 23-47.

Christian, R. E., Frick, P. J., Hill, N. L., \& Tyler, L. (1997). Psychopathy and conduct problems in children: implications for subtyping children with conduct problems. Journal of the American Academy of Child Psychology, 36, 233-241.

Cima-Knijff, M. J., \& Raine, A. (2009). Distinct characteristics of psychopathy relate to different subtypes of aggression. Personality and Individual Differences, 47, 835-840.

Cooke, D. J., \& Michie, C. (2001). Refining the construct of psychopathy: towards a hierarchical model. Psychological Assessment, 13, 171188.

Cornell, D. G., Warren, J., Hawk, G., Stafford, E., Oram, G., \& Pine, D. (1996). Psychopathy in instrumental and reactive violent offenders. Journal of Consulting and Clinical Psychology, 64, 783-790.

Dadds, M. R., Fraser, J., Frost, A., \& Hawes, D. J. (2005). Disentangling the underlying dimensions of psychopathy and conduct problems in childhood: a community study. Journal of Consulting and Clinical Psychology, 73, 400-410.

Das, J., de Ruiter, C., Lodewijks, H., \& Doreleijers, T. (2007). Predictive validity of the Dutch PCL:YV for institutional disruptive behavior: findings from two samples of male adolescents in a juvenile justice treatment institution. Behavioral Science and the Law, 25, 739-755.

Dolan, M. (2004). Psychopathic personality in young people. Advances in Psychiatric Treatment, 10, 466-473.

Douglas, K. S., Vincent, G., \& Edens, J. F. (2006). Risk for criminal recidivism: The role of psychopathy. In C. J. Patrick (Ed.), The handbook of psychopathy (pp. 533-554). New York: The Guilford Press.

Edens, J. F., Skeem, J. L., Cruise, K. R., \& Cauffman, E. (2001). Assessment of "juvenile psychopathy" and its association with violence: a critical review. Behavioral Science and the Law, 19, 53-80.

Erasmus MC. (2000). Problem behavior at school interview. Rotterdam: Department of Child and Adolescent Psychiatry.

Farrington, D. P. (2005). The importance of child and adolescent psychopathy. Journal of Abnormal Child Psychology, 33, 489-497.

Ferguson, T. J., Stegge, H., Eyre, H. L., Vollmer, R., \& Ashbaker, M. (2000). Context effects and the (mal)adaptive nature of guilt and shame in children. Genetic, Social, and General Psychology Monographs, 126, 319-345. 
Flight, J. I., \& Forth, A. E. (2007). Instrumentally violent youths: the roles of psychopathic traits, empathy and attachment. Criminal Justice and Behavior, 34, 739-751.

Forsman, M., Lichtenstein, P., Andershed, H., \& Larsson, H. (2008). Genetic effects explain the stability of psychopathic personality from mid- to late adolescence. Journal of Abnormal Psychology, $117,606-617$

Frick, P. J., \& Hare, R. D. (2001). The antisocial process screening device. Toronto: Multi-Health Systems.

Frick, P. J., \& White, S. F. (2008). Research review: the importance of callous-unemotional traits for developmental models of aggressive and antisocial behavior. The Journal of Child Psychology Psychiatry, 49, 359-375.

Frick, P. J., O’Brien, B. S., Wootton, J. M., \& McBurnett, K. (1994). Psychopathy and conduct problems in children. Journal of Abnormal Psychology, 103, 700-707.

Frick, P. J., Bodin, S. D., \& Barry, C. T. (2000). Psychopathic traits and conduct problems in community and clinic-referred samples of children: further development of the psychopathy screening device. Psychological Assessment, 12, 382-393.

Frick, P. J., Cornell, A. H., Barry, C. T., Bodin, S. D., \& Dane, H. E. (2003a). Callous-unemotional traits and conduct problems in the prediction of conduct problem severity, aggression, and self-report of delinquency. Journal of Abnormal Child Psychology, 31, 457-470.

Frick, P. J., Kimonis, E. R., Dandreaux, D. M., \& Farell, J. M. (2003b). The 4 year stability of psychopathic traits in nonreferred youth. Behavioral Science and the Law, 21, 713-736.

Frick, P. J., Stickle, T. R., Dandreaux, D. M., Farrell, J. M., \& Kimonis, E. R. (2005). Callous-unemotional traits in predicting the severity and stability of conduct problems and delinquency. Journal of Abnormal Child Psychology, 33, 471-487.

Goodman, R. (1997). The Strengths and Difficulties Questionnaire: a research note. The Journal of Child Psychology and Psychiatry, $38,581-586$.

Hare, R. D. (2003). The psychopathy checklist-revised (2nd ed.). Toronto: Multi-Health Systems.

Hawes, D. J., \& Dadds, M. R. (2007). Stability and malleability of callous-unemotional traits during treatment for childhood conduct problems. Journal of Clinical Child and Adolescent Psychology, 35, 347-355.

Johnstone, L., \& Cooke, D. J. (2004). Psychopathic-like traits in childhood: conceptual and measurement concerns. Behavioral Science and the Law, 22, 103-125.

Kiehl, K. A. (2006). A cognitive neuroscience perspective on psychopathy: evidence for paralimbic system dysfunction. Psychiatry Research, 142, 107-128.

Kimonis, E. R., Frick, P. J., Fazekas, H., \& Loney, B. R. (2006). Psychopathy, aggression, and the processing of emotional stimuli in non-referred girls and boys. Behavioral Science and the Law, 24, 21-37.

Kosson, D. S., Smith, S. S., \& Newman, J. P. (1990). Evaluating the construct validity of psychopathy in black and white male inmates: three preliminary studies. Journal of Abnormal Psychology, 99, 250-259.

Kotler, J. S., \& McMahon, R. J. (2010). The assessment of child and adolescent psychopathy. In D. Lynam \& R. T. Salekin (Eds.), Handbook of child and adolescent psychopathy (pp. 79-109). New York: The Guilford Press.

Leistico, A. M., Salekin, R. T., DeCoster, J., \& Rogers, R. (2008). A large-scale meta-analysis relating the Hare measures of psychopathy to antisocial conduct. Law and Human Behavior, 32, 28-45.

Lynam, D. R. (1997). Pursuing the psychopath: capturing the fledgling psychopath in a nomological net. Journal of Abnormal Psychology, $106,425-438$.

Lynam, D. R., \& Gudonis, L. (2005). The development of psychopathy. Annual Review of Clinical Psychology, 1, 381-407.
Lynam, D. R., Charnigo, R., Moffitt, T. E., Raine, A., Loeber, R., \& Stouthamer-Loeber, M. (2009). The stability of psychopathy across adolescence. Developmental Psychopathology, 21, 1133-1153.

Marsee, M. A., Silverthorn, P., \& Frick, P. J. (2005). The association of psychopathic traits with aggression and delinquency in non-referred boys and girls. Behavioral Science and the Law, 23, 803-817.

Moran, P., Ford, T., Butler, G., \& Goodman, R. (2008). Callous and unemotional traits in children and adolescents living in Great Britain. British Journal of Psychiatry, 192, 65-66.

Muñoz, L. C., \& Frick, P. J. (2007). The reliability, stability, and predictive utility of the self-report version of the Antisocial Process Screening Device. Scandinavian Journal of Psychology, 48, 299-312.

Muris, P., Meesters, C., Eijkelenboom, A., \& Vincken, M. (2004). The self-report version of the Strengths and Difficulties Questionnaire: its psychometric properties in 8- to 13-year-old non-clinical children. British Journal of Clinical Psychology, 43, 437-448.

Obradovic, J., Pardini, D. A., Long, J. D., \& Loeber, R. (2007). Measuring interpersonal callousness in boys from childhood to adolescence: an examination of longitudinal invariance and temporal stability. Journal of Clinical Child and Adolescent Psychology, 36, 276-292.

Pardini, D. A., \& Loeber, R. (2008). Interpersonal callousness trajectories across adolescence: early social influences and adult outcomes. Criminal Justice and Behavior, 35, 173-196.

Pardini, D. A., Lochman, J. E., \& Powell, N. (2007). The development of callous-unemotional traits and antisocial behavior in children: are there shared and/or unique predictors? Journal of Clinical Child and Adolescent Psychology, 36, 319-333.

Piatigorsky, A., \& Hinshaw, S. P. (2004). Psychopathic traits in boys with and without attention-deficit/hyperactivity disorder: concurrent and longitudinal correlates. Journal of Abnormal Child Psychology, 32, 535-550.

Porter, S., \& Woodworth, M. (2006). Psychopathy and aggression. In C. J. Patrick (Ed.), The handbook of psychopathy (pp. 481-494). New York: The Guilford Press.

Raine, A., Dodge, K., Loeber, R., Gatzke-Kopp, L. M., Lynam, D., Reynolds, C., et al. (2006). The Reactive-Proactive Aggression (RPQ) Questionnaire: differential correlates of reactive and proactive aggression in adolescent boys. Aggressive Behavior, 32, 159-171.

Salekin, R. T. (2006). Psychopathy in children and adolescents: Key issues in conceptualization and assesment. In C. J. Patrick (Ed.), The handbook of psychopathy (pp. 389-414). New York: The Guilford Press.

Seagrave, D., \& Grisso, T. (2002). Adolescent development and the measurement of juvenile psychopathy. Law and Human Behavior, 26, 219-239.

Thomaes, S., Stegge, H., Olthof, T., \& Bushman, B. J. (2008). Development and validation of the Childhood Narcissism Scale. Journal of Personality Assessment, 90, 382-391.

Van Baardewijk, Y., Stegge, H., Andershed, H., Thomaes, S., Scholte, E., \& Vermeiren, R. (2008). Measuring psychopathic traits in children through self-report. The development of the Youth Psychopathic traits Inventory-Child Version. The International Journal of Law and Psychiatry, 31, 199-209.

Wareham, J., Dembo, R., Poythress, N. G., Childs, K., \& Schmeidler, J. (2009). A latent class factor approach to identifying subtypes of juvenile diversion youths based on psychopathic features. Behavioral Sciences and the Law, 27, 71-95.

Waschbusch, D. A., \& Willoughby, M. T. (2008). Attention-deficit/ hyperactivity disorder and callous-unemotional traits as moderators of conduct problems when examining impairment and aggression in elementary school children. Aggressive Behavior, 34, 139-153.

Weiss, B., Harris, V., \& Catron, T. (2002). Development and initial validation of the peer-report measure of internalizing and externalizing behavior. Journal of Abnormal Child Psychology, 30, 285-294. 